\title{
Knowledge of Hepatitis C Screening and Management by Internal Medicine Residents: Trends Over 2 Years
}

Thomas M. Shehab, M.D., Seema Sonnad, Ph.D., Achamyeleh Gebremariam, M.S., and Philip Schoenfeld, M.D., M.S.Ed, M.Sc.(Epi)

Division of Gastroenterology, Department of Internal Medicine, and Department of Surgery, University of Michigan Health System; CHOICES (Consortium for Health Outcomes Innovation and Cost-Effectiveness Studies), University of Michigan; and Center for Excellence in Health Services Research, VAMC, Ann Arbor, Michigan

OBJECTIVES: Over 2 million people in the United States are infected with hepatitis $\mathrm{C}$, and there has been an explosion in knowledge regarding this disease in the last decade. Internal medicine residents must be able to identify patients at risk for hepatitis $\mathrm{C}$ and institute appropriate diagnostic testing and referral of these patients.

METHODS: A survey regarding hepatitis $\mathrm{C}$ risk factors and the management of hepatitis $\mathrm{C}$ patients was administered on three occasions over 15 months (time 0,1 month, and 15 months) to members of a large university-based internal medicine residency.

RESULTS: During the study period 59 residents completed all three surveys. Less than half of the residents (39\%) ask patients about hepatitis $\mathrm{C}$ risk factors. Only 58\% reported that they would refer a hepatitis $\mathrm{C}$ antibody positive patient with elevated liver enzymes to a subspecialist on the initial survey. The residents who did not refer patients cited low response rates, high side-effect profiles, and the high cost of therapy as reasons for not referring the patient. There was significant improvement $(58 \%$ vs $78 \%, p<0.01)$ in the rate of patient referral during the 15 -month study period but no substantial improvement in the other knowledge deficits.

CONCLUSIONS: The knowledge base of the internal medicine residents about hepatitis $\mathrm{C}$ screening and management is suboptimal. New, more effective hepatitis $\mathrm{C}$ education programs for internal medicine residents should be initiated. (Am J Gastroenterol 2002;97:1216-1222. (C) 2002 by Am. Coll. of Gastroenterology)

\section{INTRODUCTION}

Data from large scale epidemiological studies suggest that approximately $1.8 \%$ of the United States population is pos-

The opinions and assertions contained herein are the sole views of the authors and should not be construed as official or as representing the views of the Department of Veteran Affairs or the U.S. Government. itive for hepatitis $\mathrm{C}$ antibodies (1). During the last decade there has been an explosion of knowledge regarding the diagnosis, management, and natural history of hepatitis $\mathrm{C}$. In an effort to assimilate the information regarding this disease, the National Institutes of Health (NIH) sponsored a consensus conference on hepatitis C in March, 1997 (2). The conference culminated in the NIH Consensus Statement on Hepatitis C, a reference for physicians, patients, and the general public. However, knowledge about screening and management of hepatitis $\mathrm{C}$ may be insufficient among many physicians.

Before the NIH consensus conference, primary care physicians demonstrated multiple deficiencies in their knowledge about screening for and managing hepatitis $C(3,4)$. Primary care physicians overestimated the importance of certain risk factors (e.g., blood transfusion in 1994, casual household contact), demonstrated significant confusion over hepatitis C-specific diagnostic testing, and underreferred patients to subspecialists (3). For example, $38 \%$ of primary care physicians reported that they would not refer a hepatitis $\mathrm{C}$ antibody positive patient with elevated transaminases to a subspecialist (3). The knowledge deficits seen in this survey-based study likely translate into suboptimal patient identification, excess laboratory-related expenditures, and underreferral for ever improving hepatitis $\mathrm{C}$ therapy.

Given that internal medicine residents represent the next generation of practicing internists, it is imperative that they are able to identify patients at risk for hepatitis $\mathrm{C}$, institute appropriate initial diagnostic testing, and make appropriate referrals. However, no previous study has evaluated potential deficiencies in internal medicine residents' hepatitis $\mathrm{C}$ knowledge.

Previous research on residents' knowledge in other diseases has demonstrated knowledge deficits and suboptimal compliance with screening recommendations for breast cancer, colon cancer, and cervical cancer (5-9). In addition, previous research has demonstrated knowledge deficits in internal medicine residents regarding numerous diseases, 


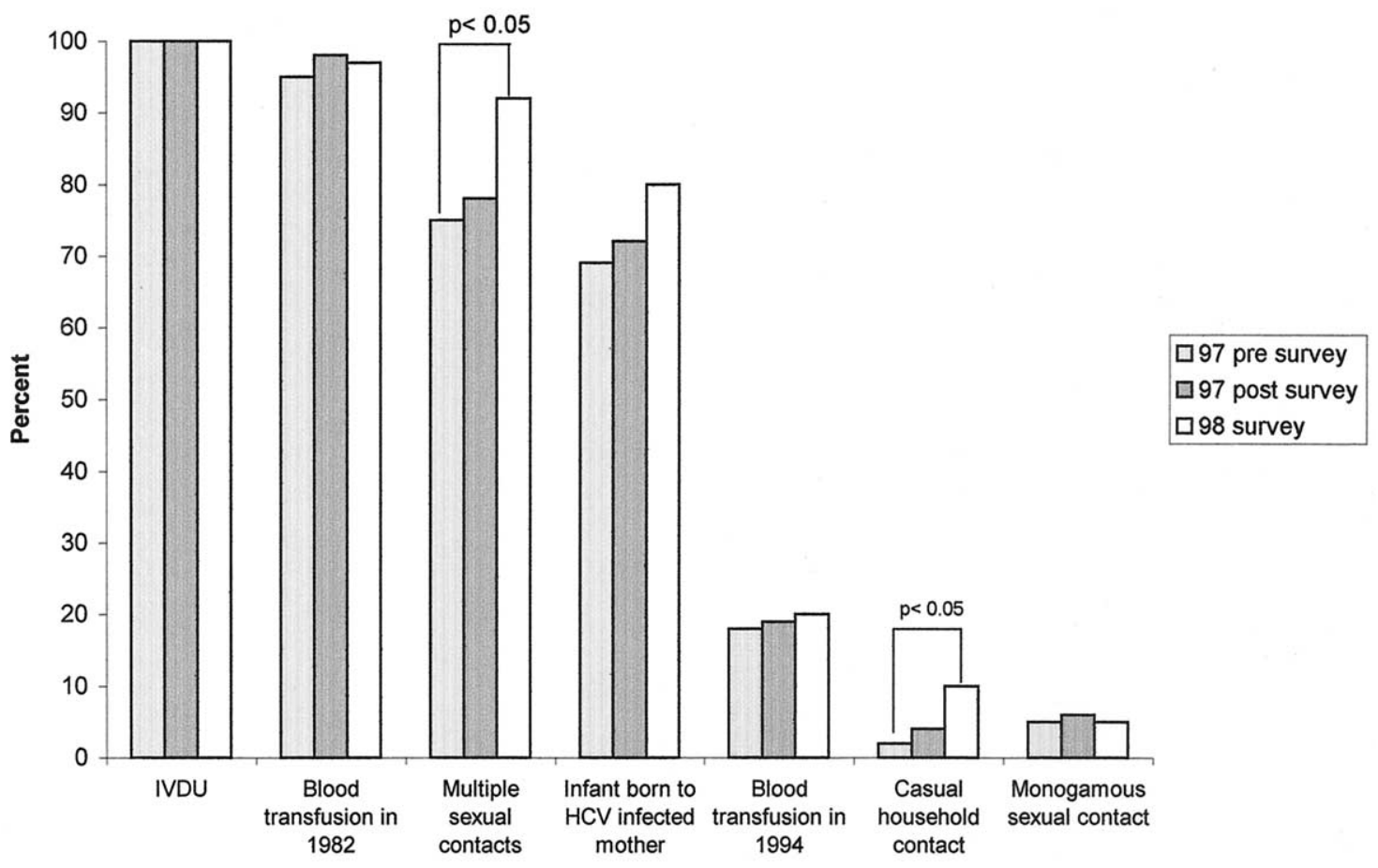

Figure 1. Percentages of respondents answering that various exposures were significant risks for acquiring hepatitis C.

specifically relating to laboratory utilization (10) and patient management $(11,12)$. It is important to determine if similar deficits exist in relation to the care of patients with hepatitis $\mathrm{C}$.

We designed this study to determine 1) the baseline knowledge of internal medicine residents regarding the diagnosis and management of HCV infection, 2) the effectiveness of passive dissemination of the NIH consensus statement as an educational tool for medicine residents, and 3 ) the change in the knowledge base of a cohort of internal medicine residents during the course of their internal medicine residency (i.e., between 1997 and 1998). Identification of knowledge gaps in the screening and management of hepatitis $\mathrm{C}$ also may facilitate the development of specific educational interventions to overcome these knowledge gaps.

\section{MATERIALS AND METHODS}

\section{Survey Design and Content}

We developed a survey to assess physicians' knowledge of the risk factors and management of patients with hepatitis C. The survey was initially developed after an evidence-based review of the relevant literature. The survey was then presented to a focus group of clinical hepatologists and a focus group of gastroenterology fellows to assess content validity. The focus groups provided written and verbal feedback on the survey and it was revised. The survey was then piloted among a cohort of primary care physicians to evaluate the clarity of survey questions and revised a second time (3).

The revised survey contained seven questions on risk factors and 10 questions on the management of patients with hepatitis C. A copy of this survey can be obtained from the authors. The questions on risk factors listed various exposures (e.g., i.v. drug use [IVDU], blood transfusion in 1982, multiple sexual partners, monogamous sexual contact), and the respondents were asked to rate each of the exposures as a "significant" or "minimal" risk factor for HCV infection (Fig. 1). Patient management questions were based on two clinical vignettes of patients who tested positive for $\mathrm{HCV}$ antibody by ELISA:

\section{Vignette 1}

55-yr-old man

- elevated ALT (150 U/L) during checkup for life insurance

- subsequent workup: anti-HCV+ (ELISA)

- otherwise healthy/asymptomatic

- history of IVDU in 1963

Vignette 2

32-yr-old woman

- anti-HCV+ (ELISA) at blood donation

- subsequent workup: normal ALT

- healthy/asymptomatic

- no risk factors

The vignette-based questions focused on physicians' decisions to refer patients, HCV testing, and attitudes toward biopsy and therapy. Based on available data, IVDU and blood transfusion in 1982 are considered to be significant HCV risk factors, whereas casual household contact and blood transfusion in 1994 are not. In addition, based on the 
$\mathrm{NIH}$ consensus statement, the patient in vignette 1 is a patient who should 1) undergo testing to confirm viremia, 2) undergo liver biopsy, and 3) be evaluated by a subspecialist to be considered for therapy.

The survey also elicited demographic information on the respondents, including year of training, number of $\mathrm{HCV}$ patients seen in the previous year, experience with interferon therapy, and experience on the gastroenterology service. The 1998 survey contained additional questions asking respondents about utilization of educational tools to learn about hepatitis C.

\section{Survey Administration}

The survey was placed in the mailbox of members of the 1st- and 2nd-yr internal medicine residents at the University of Michigan in March, 1997 (referred to as "1997 pre" group throughout). We included a cover letter explaining the purpose of the survey. The cover letter also stated that the results of individual surveys would not be shared with the residency administration. A postcard with the resident's "study" number was stapled to each survey, and when the survey was received the postcard was removed. We were therefore able to track who completed each survey but could not track the performance of an individual resident over time.

The NIH consensus statement was distributed to each resident's mailbox 2 wk after the survey. We again distributed copies of the survey $2 \mathrm{wk}$ after distributing the NIH statement ("1997 post" group). Fifteen months after the original mailing (June, 1998) the group received the survey for the third time ("1998" group).

\section{Internal Medicine Residency Population Exposure to Education About Hepatitis $\boldsymbol{C}$}

The residency surveyed is a large university-based residency with residents rotating at the tertiary care university hospital and a large Veteran's Administration hospital. The residents also have a half-day per week general medicine continuity of care clinic. The residency has a 1-hr lunchtime lecture series 4 days each week that cycles over a 24-month period. During the cycle there is one lecture on hepatitis $\mathrm{C}$ and an overview lecture on viral hepatitis (includes information on hepatitis C). Each of these lectures occurred during the study period. The residents also attend Grand Rounds $1 \mathrm{hr}$ each week, and during the study period there was one Grand Rounds session that focused on hepatitis C; the lecture was an overview of hepatitis $\mathrm{C}$ and an update on new developments. When on ambulatory rotations (3-5 months each year), the residents have a 1-hr ambulatory conference each day, and hepatitis $\mathrm{C}$ is discussed during ambulatory conferences 1-2 times each year. Most residents spend at least $2 \mathrm{wk}$ in the outpatient gastroenterology/ hepatology clinic during their residency, and all residents spend 1-2 months on the inpatient gastroenterology/hepatology service during their residency.

\section{Statistical Analysis}

The responses of the 1997 pre and 1997 post as well as the 1997 pre and 1998 surveys were compared by Student's $t$ tests for continuous data and $\chi^{2}$ tests for association for noncontinuous data. To identify factors that influence residents' responses, the responses to each question were analyzed based on year of training and the number of patients seen in the last year. A sample size of 50 residents is adequate to identify a $25 \%$ change in the proportion of residents who would refer the patient in vignette 1 to a gastroenterologist, assuming an SD of $6 \%$ and given that $\alpha=0.05$ and power $=0.80$.

\section{RESULTS}

\section{Demographic Data}

Fifty-nine residents completed all three surveys. Eleven residents ( $16 \%$ of all eligible residents) did not complete all surveys and were not analyzed. A majority of the respondents were male (64\%) (Table 1). The respondents to the 1997 survey were nearly evenly distributed between the 1stand 2nd-yr classes of the residency. When the 1997 pre and the 1998 cohorts of respondents were compared, there were significantly more residents who had done GI rotations ( $p<$ 0.01) in the 1998 group. During the 1997 presurvey and the 1997 postsurvey, the majority of internal medicine residents stated that they had cared for 1-5 patients with hepatitis C in the past year. However, when the 1997 and 1998 surveys were compared, the respondents in 1998 were more likely to have seen more HCV patients in the last year $(p<0.01)$.

At the time of the initial survey (1997 pre) only $4 \%$ of the residents had seen the NIH consensus statement, whereas $75 \%$ stated that they had seen it at the time of the 1997 postintervention survey $(p<0.00001)$ (Table 1). In the 1998 survey, $5 \%$ of the residents had not used any educational tools in the last $2 \mathrm{yr}$ to learn about hepatitis C, whereas $67 \%$ had used two or more tools. When asked to list all educational tools they had used, $62 \%$ reported using journal/review articles to learn about hepatitis $\mathrm{C}$, whereas $61 \%$ reported learning from Grand Rounds/noon conferences and $18 \%$ used online sites.

\section{HCV Screening and Risk Factor Assessment in the 1997 Postintervention Cohort}

There were no statistically significant differences between the 1997 pre and the 1997 postintervention groups with regard to risk factor knowledge or patient management (Fig. 1 and Table 3). There was a trend for all risk factors to be considered significant more often, but the differences did not reach statistical significance. In addition, when comparing the 1997 pre and post surveys, there was a trend toward increased rates of referral, biopsy, and treatment for the patient in vignette 1 . 
Table 1. Respondent Demographics

\begin{tabular}{|c|c|c|c|}
\hline & $\begin{array}{l}1997 \text { Pre } \\
(\mathrm{n}=59)\end{array}$ & $\begin{array}{l}1997 \text { Post } \\
(\mathrm{n}=59)\end{array}$ & $\begin{array}{l}1998 \text { Survey } \\
(\mathrm{n}=59)\end{array}$ \\
\hline \multicolumn{4}{|l|}{ Gender } \\
\hline Male & $64 \%$ & $64 \%$ & $64 \%$ \\
\hline Female & $36 \%$ & $36 \%$ & $36 \%$ \\
\hline Age & $28 \mathrm{yr}$ & $28 \mathrm{yr}$ & $29 \mathrm{yr}$ \\
\hline \multicolumn{4}{|l|}{ Year of training } \\
\hline 1 & $56 \%$ & $56 \%$ & $0 \%$ \\
\hline 2 & $44 \%$ & $44 \%$ & $56 \%$ \\
\hline 3 & $0 \%$ & $0 \%$ & $44 \%$ \\
\hline \multicolumn{4}{|c|}{$\begin{array}{l}\text { Have you done a } \\
\text { gastroenterology rotation }\end{array}$} \\
\hline Yes & $58 \%$ & $63 \%$ & $95 \%$ \\
\hline \multicolumn{4}{|c|}{$\begin{array}{l}\text { Number of outpatients with } \\
\text { hepatitis C cared for in } \\
\text { last year }\end{array}$} \\
\hline 0 patients & $46 \%$ & $43 \%$ & $30 \%$ \\
\hline $1-5$ patients & $49 \%$ & $52 \%$ & $59 \%$ \\
\hline $6-10$ patients & $4 \%$ & $4 \%$ & $8 \%$ \\
\hline$>10$ patients & $1 \%$ & $1 \%$ & $3 \%$ \\
\hline \multicolumn{4}{|c|}{$\begin{array}{l}\text { Have you seen the NIH } \\
\text { consensus statement? }\end{array}$} \\
\hline Yes & $4 \%$ & $75 \%$ & NA \\
\hline \multicolumn{4}{|c|}{$\begin{array}{l}\text { Did you complete this } \\
\text { survey previously? }\end{array}$} \\
\hline Yes & NA & $100 \%$ & $100 \%$ \\
\hline
\end{tabular}

\section{HCV Screening and Risk Factor Assessment in the 1998 Cohort}

In the 1998 cohort, less than half of the residents (39\%) reported asking all of their patients about hepatitis $\mathrm{C}$ risk factors (Table 2). Only 29\% would test all patients with $\mathrm{HCV}$ risk factors for hepatitis $\mathrm{C}$, and only $32 \%$ would test all patients with elevated liver enzymes for hepatitis $\mathrm{C}$.

The residents were asked to rate various exposures as "significant" or "minimal" risks for acquiring hepatitis C. The majority identified IVDU and blood transfusion in 1982 as significant risk factors in all surveys (Fig. 1). When the 1997 preintervention results were compared with the 1998

Table 2. Hepatitis C Screening

\begin{tabular}{lc}
\hline & $\begin{array}{c}1998 \text { Cohort } \\
(\mathrm{n}=59) \\
\text { (Percentage } \\
\text { Answering Yes) }\end{array}$ \\
\hline $\begin{array}{l}\text { Do you ask all patients about HCV risk } \\
\text { factors? }\end{array}$ & 39 \\
$\begin{array}{l}\text { Do you test patients for HCV } \\
\text { infection? }\end{array}$ & 45 \\
$\begin{array}{l}\text { Which of the following patients do } \\
\quad \text { you test? }\end{array}$ & \\
$\quad \begin{array}{l}\text { All patients with elevated liver } \\
\quad \text { enzymes? }\end{array}$ & 32 \\
All patients with elevated enzymes \\
$\quad$ and HCV risk factors? \\
$\quad \begin{array}{l}\text { All patients with elevated enzymes } \\
\text { and no identifiable cause? }\end{array}$ \\
$\begin{array}{l}\text { All patients with HCV risk factors } \\
\text { regardless of cause? }\end{array}$
\end{tabular}

results, the 1998 cohort was significantly more likely to answer that multiple sexual contacts $(75 \%$ vs $92 \%, p<$ $0.05)$ and casual household contact $(2 \%$ vs $10 \%, p<0.05)$ were significant risk factors. There was a trend toward all the risk factors being considered significant more frequently.

\section{Patient Management}

In the 1997 preintervention survey, a majority of the residents $(58 \%)$ reported that they would refer the patient in vignette 1 to a gastroenterologist (Table 3 ). The $42 \%$ that would not refer the patient to gastroenterology cited low response rates, high side effect profiles, and high medication cost as reasons for not referring the patient. The majority would support liver biopsy (75\%) and therapy (67\%) in the patient in vignette 1 , if recommended by a gastroenterologist. When asked which tests they would order for the patient in vignette $1,36 \%$ said they would repeat the anti-HCV (ELISA), 66\% would order anti-HCV (RIBA), and $35 \%$ would order polymerase chain reaction. In managing the patient in vignette 2, the 1997 cohort rarely would refer the patient to a gastroenterologist (16\%) and would support biopsy (32\%) and therapy (27\%) approximately a third of the time.

When the 1997 preintervention cohort and the 1998 cohort were compared, the 1998 cohort was significantly more likely to refer the patient in vignette 1 to a gastroenterologist (58\% vs $78 \%, p<0.01)$ and to support therapy (67\% vs $81 \%, p<0.05)$. The 1998 cohort was also significantly 
Table 3. Management of Patients With Hepatitis C

\begin{tabular}{|c|c|c|c|}
\hline & \multicolumn{3}{|c|}{ Percentage of Respondents Replying Yes } \\
\hline & 1997 Pre & 1997 Post & 1998 \\
\hline \multicolumn{4}{|l|}{ Vignette 1} \\
\hline \multicolumn{4}{|l|}{ At this point your next step would be to } \\
\hline reassure the patient that he or she is immune to hepatitis $\mathrm{C}$ & 0 & 0 & 0 \\
\hline observe patient in clinic; no referral & 7 & 11 & 7 \\
\hline observe in clinic; refer if symptoms develop & 35 & 27 & $13^{*}$ \\
\hline refer to a gastroenterologist & 58 & 62 & $78 *$ \\
\hline Don't know & 0 & 0 & 2 \\
\hline \multicolumn{4}{|l|}{ What tests would you do (check all that apply)? } \\
\hline Anti-HCV ELISA & 36 & 40 & 24 \\
\hline Anti-HCV by RIBA & 66 & 62 & 71 \\
\hline HCV RNA by polymerase chain reaction & 35 & 38 & $51^{*}$ \\
\hline HCV genotyping & 6 & 9 & 13 \\
\hline \multicolumn{4}{|c|}{ Would you support a liver biopsy if recommended by a gastroenterologist? } \\
\hline Yes & 75 & 77 & 82 \\
\hline \multicolumn{4}{|l|}{ Would you support therapy if recommended by a gastroenterologist? } \\
\hline Yes & 67 & 65 & $81 *$ \\
\hline \multicolumn{4}{|l|}{ If you support therapy, what regimen would you recommend? } \\
\hline Interferon for $6 \mathrm{mo}$ & NA & NA & 16 \\
\hline Interferon for $12 \mathrm{mo}$ & & & 13 \\
\hline Ribavirin alone & & & 0 \\
\hline Interferon and ribavirin & & & 60 \\
\hline Don't know & & & 11 \\
\hline \multicolumn{4}{|l|}{ Vignette 2} \\
\hline \multicolumn{4}{|l|}{ At this point your next step would be to } \\
\hline reassure the patient that he or she is immune to hepatitis $\mathrm{C}$ & 0 & 0 & 1 \\
\hline observe patient in clinic; no referral & 38 & 36 & 36 \\
\hline observe in clinic; refer if symptoms develop & 45 & 42 & 32 \\
\hline refer to a gastroenterologist & 16 & 19 & $30 *$ \\
\hline Don't know & 1 & 3 & 1 \\
\hline \multicolumn{4}{|l|}{ What tests would you do (check all that apply)? } \\
\hline Anti-HCV ELISA & 57 & 55 & 50 \\
\hline Anti-HCV by RIBA & 46 & 38 & 44 \\
\hline HCV RNA by polymerase chain reaction & 42 & 41 & $59 *$ \\
\hline HCV genotyping & 1 & $7 \dagger$ & $8^{*}$ \\
\hline \multicolumn{4}{|c|}{ Would you support a liver biopsy if recommended by a gastroenterologist? } \\
\hline Yes & 32 & 32 & 32 \\
\hline \multicolumn{4}{|l|}{ Would you support therapy if recommended by a gastroenterologist? } \\
\hline Yes & 27 & 25 & 36 \\
\hline If you support therapy, what regimen would you recommend? & NA & NA & NA \\
\hline
\end{tabular}

$\mathrm{NA}=$ not applicable.

* Denotes statistically significant difference between 1997 pre and 1998 responses $(p<0.05)$

$\dagger$ Denotes statistically significant difference between 1997 pre and 1997 post responses $(p<0.05)$.

more likely to refer the patient in vignette 2 to a gastroenterologist $(16 \%$ vs $30 \%, p<0.02)$.

\section{Treatment Recommendations}

The 1998 cohort was asked to select among therapeutic regimens for the patient in vignette 1 (Table 3). Twenty-nine percent would recommend interferon monotherapy, 60\% would recommend combination therapy with interferon and ribavirin, and $11 \%$ answered that they did not know which regimen they would order.

Of residents that chose combination therapy as the treatment of choice for the patient in vignette $1,3 \%$ expected the response rate to be approximately $75 \%, 88 \%$ expected the response rate to be $25-50 \%$ and $7 \%$ did not know the expected response rate.

\section{DISCUSSION}

Hepatitis $\mathrm{C}$ is a major health problem in the United States. It is essential for internal medicine residents to recognize patients at risk for this disease, institute proper diagnostic evaluation, and perform initial management and proper referral of these patients. In this study we used a survey to determine 1) the baseline knowledge of internal medicine residents regarding the diagnosis and management of $\mathrm{HCV}$ infection, 2) the effectiveness of passive dissemination of the NIH consensus statement as an educational tool for medicine residents, and 3) the change in the knowledge base of a cohort of internal medicine residents between 1997 and 1998.

Hepatitis C is often clinically silent until the late stage of 
the disease, and it is therefore important for physicians to be able to identify patients at risk so that proper testing can be instituted (13). Although current recommendations do not advise screening the general population for hepatitis $\mathrm{C}$ using laboratory tests, both the Centers for Disease Control and the NIH consensus conference have recommended that all patients be screened for hepatitis $\mathrm{C}$ risk factors $(2,14)$. This study is the first to specifically assess internal medicine residents' attitudes and knowledge regarding screening and testing for hepatitis C. Despite recommendations to ask all patients about hepatitis $\mathrm{C}$ risk factors, more than half of the residents reported that they do not do so. This may result in significant underrecognition of patients with clinically silent disease. It is clear from these data that hepatitis C-specific teaching directed at residents must stress the importance of inquiring about risk factors for hepatitis $\mathrm{C}$ and define the spectrum of patients that warrants HCV testing.

To recognize patients at risk for hepatitis $\mathrm{C}$, physicians must have adequate knowledge of the risk factors for the disease. The residents surveyed in this study were able to assess the risk level for most exposures. Our study, however, did not assess the actual rates of asking about specific risk factors or the manner in which they inquired about risk factors. Previous research has demonstrated that patients are often evasive about answering questions regarding subjects such as IVDU, multiple sexual partners, and cocaine use (15).

The NIH consensus conference would say that the patient in vignette 1 is a patient who should undergo further testing, liver biopsy, and, likely, therapy (2). The respondents in this study demonstrated considerable confusion in the ordering of appropriate laboratory tests. Thirty-six percent of the 1997 respondents would needlessly repeat the HCV antibody test via ELISA, and 66\% would order RIBA for the patient in vignette 1 . In this patient with risk factors and elevated enzymes, the pretest probability that the original anti-HCV (ELISA) is a "true positive" is extremely high, and therefore further antibody testing would be unnecessary $(14,16,17)$. Similar findings were seen in the 1998 survey, and the confusion over additional testing may lead to excessive health care expenditures.

In 1997, only $58 \%$ of the residents said they would refer the patient in vignette 1 to a gastroenterologist. Over the 15 months between the first and last surveys, the percentage of residents referring the patient to a gastroenterologist and supporting therapy increased significantly. However, even in 1998, 22\% would not refer this patient to a gastroenterologist. Given that the current practice in the United States is for subspecialists to administer hepatitis C therapy, these data suggest that a significant proportion of hepatitis $\mathrm{C}$ patients in the United States will not have access to treatment.

Previously we assessed the knowledge regarding HCV among primary care physicians (3). The first portion of the current study was done within a month of the study of the primary care physicians. The knowledge of internal medi- cine residents was comparable to the knowledge of primary care physicians in practice. The primary care physicians studied were members of a large health maintenance organization owned by the university where the residents trained. The similarity in knowledge between the two groups may reflect the passage of knowledge and practice patterns from the practicing physicians to the residents.

In this study we did not show an impact of the NIH consensus statement as an educational tool. This study does not prove that the statement is an ineffective educational tool, given that the methodology of this study may have limited the effectiveness in many ways. The methodological limitations include 1) the consensus statement was placed in the residents' mailboxes with no supporting information, 2) we did not identify from whom the consensus statement was sent, and 3) we did not inform the residents that they would be resurveyed about hepatitis $\mathrm{C} 1$ month after receiving the survey. In addition, we did not collect data regarding how much, if any, of the NIH statement the residents read. Previous research regarding the education of physicians and physicians in training suggests that 13 pages of text placed in a resident's mailbox is a suboptimal educational tool compared with interactive or even didactic learning sessions $(18-20)$.

The findings of this study demonstrate significant knowledge deficits that likely translate into suboptimal patient care. However, this study has several limitations. First, we recognize that self-reported knowledge does not necessarily translate into the care the physician provides. Second, this study was performed at a single institution and may not reflect the current level of knowledge nationally among internal medicine residents. Finally, if a similar study is done in the future it will be important to track the performance of individual residents over time and to assess the impact of more effective educational interventions on their learning.

In summary, internal medicine residents' knowledge regarding hepatitis $\mathrm{C}$ is suboptimal but similar to that of practicing physicians in the same state. Acknowledging that hepatitis $\mathrm{C}$ is only one of many diseases about which residents must learn, specific educational tools are needed to optimize their knowledge of this disease. The availability of easily accessible, easy-to-use hepatitis $\mathrm{C}$-specific guidelines may help residents in the initial management of hepatitis $\mathrm{C}$ patients. Also, standardized patient questionnaires that contain sensitive and specific questions regarding risk factors for hepatitis $\mathrm{C}$ may optimize patient identification. Finally, hepatitis $\mathrm{C}$-specific educational interventions should be interactive and case based rather than classic didactic lectures. In the future, education of internal medicine residents regarding hepatitis $\mathrm{C}$ should focus on recognition of asymptomatic patients and proper initial evaluation and testing. In addition, an effort must be made to increase the frequency of residents inquiring about hepatitis $\mathrm{C}$ risk factors to optimize patient identification. 


\section{ACKNOWLEDGMENT}

The authors thank Dr. Anna S. F. Lok for her advice regarding the design of this project and the preparation of the manuscript.

Reprint requests and correspondence: Thomas M. Shehab, M.D., University of Michigan Medical Center, 3912 Taubman Center, Box 0362, 1500 East Medical Center Drive, Ann Arbor, MI 48109-0362.

Received Mar. 7, 2001; accepted Sep. 27, 2001.

\section{REFERENCES}

1. Alter MJ, Kruszon-Moran D, Nainan OV, et al. The prevalence of Hepatitis C virus infection in the United States, 1988 through 1994. N Engl J Med 1999;341:556-62.

2. Powell DW. National Institutes of Health consensus development conference panel statement: Management of hepatitis C. Hepatology 1997;26(suppl 1):2S-10S.

3. Shehab TM, Sonnad SS, Jeffries M, et al. Current practice patterns of primary care physicians in the management of patients with hepatitis C. Hepatology 1999;30:794-800.

4. Saeian K, Rochling FA, Burke R, et al. Faculty and trainee knowledge of hepatitis $\mathrm{C}$ infection at a tertiary care medical center. WMJ 1998;97:43-6.

5. Borum ML. Breast cancer surveillance: Ambulatory care focus in residency may influence practice patterns. Am J Med Sci 1996;312:123-5.

6. McPhee SJ, Richard RJ, Solkowitz SN. Performance of cancer screening in a university internal medicine practice: Comparison with the 1980 American Cancer Society guidelines. J Gen Intern Med 1986;1:275-81.

7. Lynch GR, Prout MN. Screening for cancer by residents in an internal medicine program. Med Educ 1986;61:387-93.

8. Borum ML. Cancer screening in women by internal medicine resident physicians. South Med J 1997;90:1101-5.
9. Sharma VK, Corder FA, Raufman JP, et al. Survey of internal medicine residents' use of the fecal occult blood test and their understanding of colorectal cancer screening and surveillance. Am J Gastroenterol 2000;95:2068-73.

10. Yarnold PR, Martin GJ, Feinglass J, et al. First-year residents' caring, medical knowledge, and clinical judgement in relation to laboratory utilization. Acad Med 1994;69:996-8.

11. Bernard AM, Anderson L, Cook CB, et al. What do internal medicine residents need to know to enhance their diabetes care? Diabetes Care 1999;22:661-6.

12. Reichert S, Simon T, Halm EA. Physicians' attitudes about prescribing and knowledge of the costs of common medications. Arch Intern Med 2000;160:2799-803.

13. Sharara AI, Hunt CM, Hamilton JD. Hepatitis C. Ann Intern Med 1996;125:658-68.

14. Recommendations for prevention and control of hepatitis $\mathrm{C}$ virus (HCV) infection and $\mathrm{HCV}$-related chronic disease. Centers for Disease Control and Prevention. MMWR Recomm Rep 1998;47(RR-19):1-39.

15. Conry-Cantilena C, VanRaden M, Gibble J, et al. Routes of infection, viremia, and liver disease in blood donors found to have hepatitis C virus infection. N Engl J Med 1996;334: 1691-6.

16. Lok ASF, Gunaratnum NT. Diagnosis of hepatitis C. Hepatology 1997:26(suppl 1):48S-56S.

17. Gretch DR. Diagnostic tests for hepatitis C. Hepatology 1997; 26(suppl 1):43S-7S.

18. Davis D, O'Brien MAT, Freemantle N, et al. Impact of formal continuing medical education: Do conferences, workshops, rounds and other traditional continuing education activities change physician behavior or health care outcomes? JAMA 1999;282:867-74.

19. Davis DA, Thomson MA, Oxman AD, et al. Changing physician performance. A systematic review of the effect of continuing medical education strategies. JAMA 1995;274:700-5.

20. Madan AK, Caruso BA, Lopes JE, et al. Comparison of simulated patient and didactic methods of teaching HIV risk factors assessment to medical residents. Am J Prev Med 1998; $15: 114-9$. 